\title{
Time to Administration of Antibiotics among Inpatients with Severe Sepsis or Septic Shock
}

\author{
Katie Mok, Michael D Christian, Sandra Nelson, and Lisa Burry
}

\begin{abstract}
Background: Current evidence suggests that administration of appropriate antibiotic therapy within $1 \mathrm{~h}$ after the onset of hypotension significantly improves mortality rates among patients with severe sepsis and septic shock.

Objectives: To determine the interval from recognition of severe sepsis or septic shock in inpatients to initial administration of antibiotic and to assess institutional compliance with the Surviving Sepsis Campaign's recommendation for early antibiotic therapy.
\end{abstract}

Methods: A 6-month retrospective chart analysis was conducted to determine the interval from documented onset of hypotension to initial administration of antibiotic for patients with severe sepsis or septic shock. Patients who were admitted to a general medicine ward, a surgery ward, or the intensive care unit (ICU) of a 475-bed university-affiliated hospital and who met the criteria for severe sepsis or septic shock were eligible for inclusion. Patients who received antibiotics before meeting the criteria for severe sepsis or septic shock were excluded.

Results: Charts for 100 patients with severe sepsis or septic shock were reviewed. The mean age was 69.0 years (standard deviation 18.7 years), and $56 \%$ were men. The median interval from onset of severe sepsis or septic shock to administration of antibiotic was $4.00 \mathrm{~h}$ (interquartile range $[\mathrm{IQR}] 1.80-6.45 \mathrm{~h}$ ). The median interval from the time a physician ordered an antibiotic to administration of the drug was $1.28 \mathrm{~h}$ (IQR 0.57-3.05 h). The interval between ordering and administration differed significantly for patients on the wards $(5.67 \mathrm{~h})$, those with onset in the ICU $(4.00 \mathrm{~h})$, and those with onset in the emergency department (3.28 h) $(p=0.039)$. The overall survival rate was $56 \%$.

Conclusion: At the study hospital, the interval from onset of severe sepsis or septic shock to initial administration of antibiotic to inpatients exceeded the 1-h period recommended by the Surviving Sepsis Campaign. These results will be used as a baseline for future quality assurance and improvement initiatives aimed at minimizing the time to antibiotic administration for this group of patients, who are at high risk of death.

Keywords: antibiotics, severe sepsis, septic shock, timing

\section{RÉSUMÉ}

Contexte : D'après les données probantes actuelles, l'administration d'une antibiothérapie adéquate dans l'heure suivant la survenue d'hypotension aide grandement à réduire le taux de mortalité chez les patients atteints de sepsis sévère ou de choc septique.

Objectifs : Déterminer quel est l'intervalle séparant le diagnostic du sepsis sévère ou du choc septique de l'administration initiale d'un antibiotique aux patients hospitalisés et évaluer le degré de conformité de l'établissement envers la recommandation de la campagne "Surviving Sepsis " (survivre au sepsis) qui préconise une antibiothérapie précoce.

Méthodes: Une analyse rétrospective couvrant six mois de dossiers médicaux a été effectuée dans le but de déterminer l'intervalle entre la survenue consignée de l'hypotension et l'administration initiale d'un antibiotique chez des patients atteints de sepsis sévère ou de choc septique. Les patients qui étaient admis à un service de médecine générale ou de chirurgie ou à l'unité de soins intensifs (USI) d'un hôpital universitaire de 475 lits et qui répondaient aux critères d'un sepsis sévère ou d'un choc septique étaient admissibles à l'étude. Ceux qui ont reçu des antibiotiques avant de satisfaire aux critères d'un sepsis sévère ou d'un choc septique ont été exclus.

Résultats : Les dossiers médicaux de 100 patients atteints de sepsis sévère ou de choc septique ont été étudiés. Lâge moyen était de 69,0 ans (écart-type de 18,7 ans) et $56 \%$ des patients étaient des hommes. Lintervalle médian entre le moment du diagnostic d'un sepsis sévère ou d'un choc septique et celui de l'administration d'un antibiotique était de $4,0 \mathrm{~h}$ (écart interquartile [ÉIQ] de 1,80 à 6,45 h). L'intervalle médian entre le moment où le médecin prescrivait un antibiotique et l'administration de celui-ci était de $1,28 \mathrm{~h}$ (EIQ de 0,57 à 3,05 h). L'intervalle entre le moment de la prescription et celui de l'administration était beaucoup plus important pour les patients chez qui un sepsis sévère ou un choc septique apparaissait alors quils se trouvaient au service de chirurgie ou de médecine générale $(5,67 \mathrm{~h})$ que pour les patients qui étaient à l'USI $(4,00 \mathrm{~h})$ ou au service des urgences $(3,28 \mathrm{~h})(p=0,039)$. Le taux de survie global était de $56 \%$.

Conclusion : À l'hôpital où s'est déroulée l'étude, l'intervalle entre les premières manifestations d'un sepsis sévère ou d'un choc septique et le moment où l'antibiotique était administré aux patients excédait la période d'une heure recommandée par la campagne «Surviving Sepsis» (survivre au sepsis). Ces résultats serviront de référence pour de futurs programmes d'amélioration et d'assurance de la qualité dont l'objectif sera de réduire au maximum la période de temps située entre le diagnostic et l'administration de l'antibiotique pour ce groupe de patients qui présente un risque élevé de mortalité.

Mots clés : antibiotiques, sepsis sévère, choc septique, rapidité d'intervention

[Traduction par l'éditeur] 


\section{INTRODUCTION}

Severe sepsis and septic shock continue to represent a growing health care burden in Canada and worldwide, with higher associated mortality rates and resource consumption than for nonsevere sepsis conditions. In 2008/2009 across Canada, the mortality rate was $45.2 \%$ among patients with severe sepsis, compared to $20.9 \%$ for patients with sepsis that did not progress to severe. ${ }^{1}$ Hospital admission rates in Canada for severe sepsis (including septic shock) increased by $18.0 \%$ from 2004 to 2009 , and severe sepsis and septic shock accounted for $40.0 \%$ of all hospital admissions for sepsis in 2008/2009.' Of particular interest, the mortality rate was $56.0 \%$ higher for inpatients in whom sepsis developed after admission to hospital than for patients who presented with sepsis that developed before admission. ${ }^{2}$

Considering the impact of severe sepsis on patient outcomes and on the health care system, comprehensive management strategies have been developed to improve early recognition and timely interventions.-5 The Surviving Sepsis Campaign promotes management options that include early hemodynamic optimization with goal-directed therapy (known as early goal-directed therapy or EGDT), early initiation of appropriate antibiotics, and low-tidal volume mechanical ventilation, among other actions. ${ }^{4,6}$ Guidelines from the campaign recommend initiation of broad-spectrum antibiotics within $1 \mathrm{~h}$ of recognition of severe sepsis or septic shock, a reflection of increasing evidence that supports timely and appropriate antibiotic therapy to improve morbidity and mortality in this patient population. ${ }^{7-12}$ In a retrospective cohort study of patients with septic shock in the intensive care unit (ICU), Kumar and others ${ }^{8}$ observed a $7.6 \%$ reduction in survival with each hour of delay in initiating effective antimicrobial therapy from the onset of hypotension. Existing literature has examined the delay in antibiotic therapy and its impact on patients with severe sepsis in the ICU and the emergency department, but few have studied inpatients in other hospital locations or factors that affect time to administration.

The objective of this study was to determine the interval from recognition of severe sepsis or septic shock to initial antibiotic administration among inpatients on general medicine or surgery wards or in the ICU. In addition, the study examined the appropriateness of empiric antimicrobial therapy and survival to discharge.

\section{METHODS}

\section{Study Design and Setting}

This study was a single-centre, retrospective chart analysis of patients in a general medicine ward, a general surgery ward, and the ICU of a 475-bed university-affiliated hospital.
Patients were identified from medical records for the 6-month timeframe from August 1, 2009, to January 31, 2010, inclusive. This period preceded implementation of computerized practitioner order entry (CPOE) at this institution, to allow for future comparison with a post-CPOE cohort. Pharmacy services included drug distribution from 0800 to 2100 on weekdays and from 0800 to 1700 on weekends. Medications were also available through a night cupboard system after regular pharmacy hours. The study protocol was approved by the hospital's Research Ethics Board. The requirement for patient consent was waived, because the study was a retrospective, observational, quality assurance initiative.

\section{Study Population}

Patients were included if they were 18 years of age or older, had been treated within the defined study period on the specified patient wards, had a first encounter of severe sepsis or septic shock, and were started on IV antibiotic therapy. Severe sepsis was defined as sepsis associated with organ dysfunction, hypoperfusion, or hypotension, whereas septic shock was defined as sepsis with hypotension despite adequate fluid resuscitation. ${ }^{13}$ For patients with multiple episodes of sepsis within the study period, only data from the first such episode within the defined time period were included in the analysis. The following patients were excluded: those who had received IV antibiotics before development of severe sepsis or septic shock, those who had severe sepsis or septic shock but for whom times of antibiotic orders and administration were undocumented, and those with severe sepsis or septic shock who did not receive antibiotics.

A combination of approaches was used to identify patients with severe sepsis or septic shock. A list of patients who received IV antibiotic therapy was generated from the pharmacy computer system (PowerVision, Cerner Corporation, Markham, Ontario) and was cross-referenced with computergenerated lists of patients who met criteria from the 2001 International Sepsis Definitions Conference for severe sepsis and septic shock, ${ }^{14}$ including hypotension (systolic blood pressure $<90 \mathrm{~mm} \mathrm{Hg}$ ), despite adequate fluid resuscitation or use of vasopressors; and lactate greater than $2 \mathrm{mmol} / \mathrm{L}$, as recorded in the patient's electronic chart database. The patient database of the hospital's Critical Care Outreach Team was also used, as a majority of ward patients with signs and symptoms of severe sepsis or septic shock are referred for evaluation. These lists were cross-referenced using Microsoft Excel 2003 to identify patients with a combination of these features, for whom charts were reviewed manually.

\section{Data Collection}

Data were extracted from the patients' medical records using a standardized case report form. We collected demo- 
graphic data (age, sex, admission diagnosis, type of admission, patient location, comorbidities, presumed cause of infection, date of admission, and date of discharge or death), clinical data (temperature, heart rate, systolic blood pressure, oxygen requirement, urine output, white blood cell count, creatinine, bilirubin, platelet count, international normalized ratio, lactate level, time of onset of severe sepsis or septic shock, time of consultation with the Critical Care Outreach Team, and culture results), and antibiotic data (drug name, dosage regimen, time of antibiotic order by physician, time of order entry by pharmacist, and time of antibiotic administration).

\section{Outcome Measures}

The primary outcome was the interval from documented onset of severe sepsis or septic shock to initial antibiotic administration (measured in hours). Onset of severe sepsis or septic shock was defined as the earliest of either the first documented episode of hypotension, elevated lactate, or consultation with the Critical Care Outreach Team for hypotension or septic shock. Various intervals to antibiotic delivery were also analyzed, including time from documented onset of sepsis to physician order and pharmacist order entry and time from physician order to antibiotic administration. Secondary outcomes were appropriateness of empiric antimicrobial therapy (as determined by match with culture sensitivities) and survival to hospital discharge.

\section{Data Analysis}

All collected data were entered into a database created with Microsoft Excel 2003, and a data check was then performed. Descriptive statistics were used to summarize the collected data: medians (and interquartile ranges [IQRs]) for time intervals, means (and standard deviations [SDs]) for continuous data, and frequencies and percentages for categorical data. The $\chi^{2}$ or Fisher exact test was used to compare dichotomous variables, and a $p$ value of less than 0.05 was considered statistically significant. A subgroup analysis using one-way analysis of variance (ANOVA) was conducted to identify the presence of heterogeneity among the various inpatient locations. All statistical analyses were performed with SPSS software for Windows, version 9.1 (IBM, Armonk, New York).

\section{RESULTS}

\section{Baseline Patient Characteristics}

Within the defined study period, 100 patients with severe sepsis or septic shock met the inclusion criteria (out of 362 patients whose charts were screened). Of the excluded patients, 136 did not meet criteria for severe sepsis or septic shock, 118 had antibiotic therapy that was initiated before progression to severe sepsis or septic shock, and 8 were excluded for other reasons such as missing time data. Patients' demographic and clinical characteristics are summarized in Table 1. The mean patient age was 69.0 years (SD 18.7 years), and 56\% were male. Major comorbidities included coronary artery disease (41\%), renal failure $(26 \%)$, diabetes mellitus $(24 \%)$, and active

\section{Table 1. Baseline Characteristics of Patients Who Met Criteria for Severe Sepsis or Septic Shock}

\begin{tabular}{|c|c|}
\hline Characteristic & $\begin{array}{l}\text { No. }(\% \text { of } \\
\text { Patients)* }\end{array}$ \\
\hline No. of patients & 100 \\
\hline Age (years), mean \pm SD & $69.0 \pm 18.7$ \\
\hline Sex, male & $56(56)$ \\
\hline \multicolumn{2}{|l|}{ Admitting service } \\
\hline General medicine & $51(51)$ \\
\hline General surgery & 19 (19) \\
\hline Intensive care unit & $30(30)$ \\
\hline \multicolumn{2}{|l|}{ Diagnosis } \\
\hline Severe sepsis & $60(60)$ \\
\hline Septic shock & $40(40)$ \\
\hline \multicolumn{2}{|l|}{ Comorbidities } \\
\hline Immunocompromise & 19 (19) \\
\hline Cancer (active malignancy) & $23(23)$ \\
\hline Liver disease & $11(11)$ \\
\hline Heart failure & $20(20)$ \\
\hline COPD & $10(10)$ \\
\hline Renal failure & $26(26)$ \\
\hline Diabetes mellitus & $24(24)$ \\
\hline Coronary artery disease & $41(41)$ \\
\hline Substance abuse, documented & $7(7)$ \\
\hline Alcohol abuse, documented & $5(5)$ \\
\hline Smoker, documented & $13(13)$ \\
\hline \multicolumn{2}{|l|}{ Duration of hospital stay, days } \\
\hline Mean \pm SD & $25.7 \pm 38.9$ \\
\hline Median (range) & $11(0-214)$ \\
\hline \multicolumn{2}{|l|}{ Systemic response } \\
\hline Hyperthermia (temperature $>38^{\circ} \mathrm{C}$ ) & $34(34)$ \\
\hline Hypothermia (temperature $<36^{\circ} \mathrm{C}$ ) & $13(13)$ \\
\hline Tachycardia (HR > 90 beats/min) & $85(85)$ \\
\hline Tachypnea (RR > 20 breaths/min) & $76(76)$ \\
\hline Leukocytosis (WBC > 12 × 10\%/L) & $68(68)$ \\
\hline Leukopenia (WBC < 4 × 10\%/L) & $8(8)$ \\
\hline \multicolumn{2}{|l|}{ Organ dysfunction } \\
\hline $\mathrm{SBP}<90 \mathrm{~mm} \mathrm{Hg}$ or MAP $<65 \mathrm{~mm} \mathrm{Hg}$ & $75(75)$ \\
\hline Lactate $>2 \mathrm{mmol} / \mathrm{L}$ & $93(93)$ \\
\hline $\mathrm{O}_{2}$ saturation $<90 \%$ (room air) & $57(70)$ \\
\hline $\begin{array}{l}\text { Urine output }<0.5 \mathrm{~mL} / \mathrm{kg} \text { per hour } \\
\text { for }>2 \mathrm{~h}(n=32)\end{array}$ & $16(50)$ \\
\hline Creatinine $>177 \mathrm{mmol} / \mathrm{L}$ & $26(26)$ \\
\hline Bilirubin $>70 \mathrm{mmol} / \mathrm{L}$ & 4 (4) \\
\hline Platelet count $<100 \times 10^{9} / \mathrm{L}$ & $15(15)$ \\
\hline INR $>1.5$ or $\mathrm{aPTT}>60 \mathrm{~s}$ & $25(27)$ \\
\hline \multicolumn{2}{|c|}{$\begin{array}{l}\text { aPTT = activated partial thromboplastin time, } \\
\text { COPD = chronic obstructive pulmonary disease, } \\
\text { HR = heart rate, INR = international normalized ratio, } \\
\text { MAP = mean arterial pressure, RR = respiratory rate, } \\
\text { SBP = systolic blood pressure, SD = standard deviation, } \\
\text { WBC = white blood cells. } \\
\text { *Except where indicated otherwise. }\end{array}$} \\
\hline
\end{tabular}


Table 2. Sources of Infection among Patients with Severe Sepsis or Septic Shock

\begin{tabular}{lrr} 
Source of infection & $\begin{array}{c}\text { No. (\%) of Patients } \\
(\boldsymbol{n}=\mathbf{1 0 0})\end{array}$ \\
\hline Lungs (pneumonia) & 31 & $(31)$ \\
Abdomen & 30 & $(30)$ \\
Urinary tract & 20 & $(20)$ \\
Bloodstream or catheter & 4 & $(4)$ \\
Wound & 4 & $(4)$ \\
Bone or joint & 2 & $(2)$ \\
Endocarditis & 1 & $(1)$ \\
Skin or soft tissue & 1 & $(1)$ \\
Unknown & 6 & $(6)$ \\
Other & 1 & $(1)$ \\
\hline
\end{tabular}

Table 3. Culture Results

\begin{tabular}{|c|c|c|}
\hline Culture Data & $\begin{array}{l}\text { No. }(\%) \\
\text { or Or }\end{array}$ & $\begin{array}{l}\text { of Patients } \\
\text { yanisms* }\end{array}$ \\
\hline Total no. of patientst & 100 & \\
\hline With negative culture results & 35 & (35) \\
\hline With positive culture result & 64 & (64) \\
\hline $\begin{array}{l}\text { Sample type for positive culture results } \\
\text { ( } n=64 \text { patients) }\end{array}$ & & \\
\hline Blood (central or peripheral) & 62 & $(97)$ \\
\hline Urine & 18 & (28) \\
\hline Sputum & 8 & $(12)$ \\
\hline Wound & 5 & (8) \\
\hline Polymicrobial & 3 & $(5)$ \\
\hline Total no. of organisms isolated $\neq$ & 68 & \\
\hline Gram-positive organisms & 26 & $(38)$ \\
\hline Enterococcus & 3 & (4) \\
\hline Streptococcus pneumoniae & 5 & (7) \\
\hline MSSA & 5 & (7) \\
\hline MRSA & 2 & (3) \\
\hline Streptococcus viridans & 2 & (3) \\
\hline Coagulase-negative Staphylococcus & 8 & $(12)$ \\
\hline Other & 1 & $(1)$ \\
\hline Gram-negative organisms & 38 & (56) \\
\hline Escherichia coli & 11 & (16) \\
\hline Klebsiella & 9 & (13) \\
\hline Pseudomonas & 8 & (12) \\
\hline Citrobacter & 1 & $(1)$ \\
\hline Acinetobacter & 1 & (1) \\
\hline Proteus & 3 & (4) \\
\hline Morganella & 1 & (1) \\
\hline Other & 4 & (6) \\
\hline Anaerobic organisms & 4 & (6) \\
\hline Clostridium difficile & 1 & (1) \\
\hline Bacteroides fragilis & 1 & (1) \\
\hline Other & 2 & (3) \\
\hline
\end{tabular}

MRSA = methicillin-resistant Staphylococcus aureus,

MSSA = methicillin-sensitive Staphylococcus aureus.

*Except where indicated otherwise.

tFor one patient, no samples were drawn for culture. ¥Percentages of organisms were calculated using total number of organisms isolated as the denominator.
Table 4. Initial Empiric Antibiotic Use

\begin{tabular}{lrr} 
Variable & $\begin{array}{r}\text { No. (\%) of Patients } \\
\text { or Antibiotics }\end{array}$ \\
\hline No. of initial antibiotics ( $\boldsymbol{n}=\mathbf{1 0 0}$ patients) & 46 & $(46)$ \\
1 & 41 & $(41)$ \\
2 & 13 & $(13)$ \\
3 & 2 & $(1.2)$ \\
Initial drug, by class ( $\boldsymbol{n}=\mathbf{1 6 7}$ antibiotics) & $9(5.4)$ \\
Aminoglycosides & $30(18.0)$ \\
Carbapenems & $4(2.4)$ \\
Cephalosporins & $6(3.6)$ \\
Clindamycin & $2(1.2)$ \\
Macrolides & $35(21.0)$ \\
Penicillins & $28(16.8)$ \\
Penicillin combination (pipercillin-tazobactam) & $23(13.8)$ \\
Fluoroquinolones & $26(15.6)$ \\
Metronidazole & $2(1.2)$ \\
Vancomycin &
\end{tabular}

malignancy (23\%). Onset of severe sepsis or septic shock occurred on the wards for 29 patients, in the ICU for 10, and in the emergency department for 61 .

The most common presumed sources of infection were lung $(31 \%)$, abdomen $(30 \%)$, and urinary tract $(20 \%)$. The source of sepsis was unknown for $6 \%$ of patients (Table 2). Microbiology results are presented in Table 3. Of the 64 positive culture results, $3(5 \%)$ were polymicrobial. Twenty-six $(38 \%)$ of the 68 organisms isolated were gram-positive, 38 (56\%) were gram-negative, and $4(6 \%)$ were anaerobic. The initial number of empiric IV antibiotics used ranged from 1 to 3 (Table 4).

\section{Primary Outcome: Time to Antibiotic Administration}

The overall median time (and IQR) from onset to administration of antibiotics was 4.00 hours (IQR 1.80-6.45 h). Of the 100 patients, only $6 \%$ received antibiotics within $1 \mathrm{~h}$ of onset of severe sepsis or septic shock. Examination of various components of antibiotic delivery showed that the median times (and IQR) from documented onset of severe sepsis or septic shock to physician order and pharmacist order entry were $1.45 \mathrm{~h}$ (IQR 0.58-4.21 h) and 10.62 h (IQR 4.43-17.32 h), respectively. The intervals to pharmacist order entry were often extended because of overnight orders that were not entered into the patients' electronic records until the following day. The median interval from creation of the antibiotic order by a physician to actual administration was $1.28 \mathrm{~h}$ (IQR $0.57-3.05 \mathrm{~h}$ ), with an average of $2.26 \mathrm{~h}$ (SD 2.78). There was a statistically significant difference in the median interval to antibiotic administration depending on the location of onset of severe sepsis or septic shock: $5.67 \mathrm{~h}$ (IQR 4.13-15.21 h) for onset in 
the general surgery and medicine wards, $4.00 \mathrm{~h}$ (IQR $4.00-4.00 \mathrm{~h}$ ) for onset in the ICU, and $3.28 \mathrm{~h}$ (IQR 1.37-5.35 h) for onset in the emergency department $(p=0.039)$. However, similar heterogeneity among the various locations was not observed for the intervals to physician order or pharmacist order entry (Figure 1).

\section{Secondary Outcomes}

Of the 64 patients with positive culture results, 54 (84\%) received appropriate empiric antimicrobial therapy, relative to observed sensitivities. The overall survival rate was $56 \%$. The survival to hospital discharge was $61 \%$ (33/54) among patients who received appropriate empiric antibiotics and 30\% (3/10) among those who did not receive appropriate empiric therapy $(p=0.19)$.

\section{DISCUSSION}

For most patients with severe sepsis or septic shock after hospital admission, the interval from recognition of onset to antibiotic administration exceeded the 1-h recommendation set forth by the Surviving Sepsis Campaign. Although past studies have evaluated the impact of delay of administration in the ICU and the emergency department, this single-centre retrospective quality improvement study is, to the authors' knowledge, the first to determine the timeframe for patients in general surgery and general medicine wards. The study cohort was also broader than those in previous studies, including patients with both severe sepsis and septic shock. The overall delay of $4.00 \mathrm{~h}$ (IQR 1.80-6.45 h) was comparable to delays reported from other institutions. ${ }^{8,10,12}$ This significant delay in time to antibiotic administration warrants assessment of contributing factors to allow development of methods that will minimize the interval for this group of patients, who are at high risk of death.

Management of severe sepsis and septic shock involves multiple modalities, including initial resuscitation, antibiotic therapy, identification and control of the source of infection, and the use of fluids, vasopressors, and inotropes in the ICU. Several recent studies have confirmed and emphasized the importance of timely and appropriate antibiotic treatment in improving morbidity and mortality among patients with severe sepsis or septic shock. In their 2006 study, Kumar and others ${ }^{8}$ found that survival dropped by $7.6 \%$ with each hour of delay to initiation of effective antimicrobial therapy (in the first $6 \mathrm{~h}$ after onset of hypotension) among patients with septic shock in the ICU. Previous studies have also shown increased mortality with delays in antibiotic administration within specific patient populations with severe pneumonia, ${ }^{11,15-17}$ bacterial meningitis, ${ }^{18,19}$ and Staphylococcus aureus bacteremia. ${ }^{20}$ More recently, Gaieski and others' studied the impact of time to antibiotic administration on survival among patients with severe sepsis or septic shock in the emergency department. They found a $13.7 \%$ decrease in mortality for patients with EGDT who

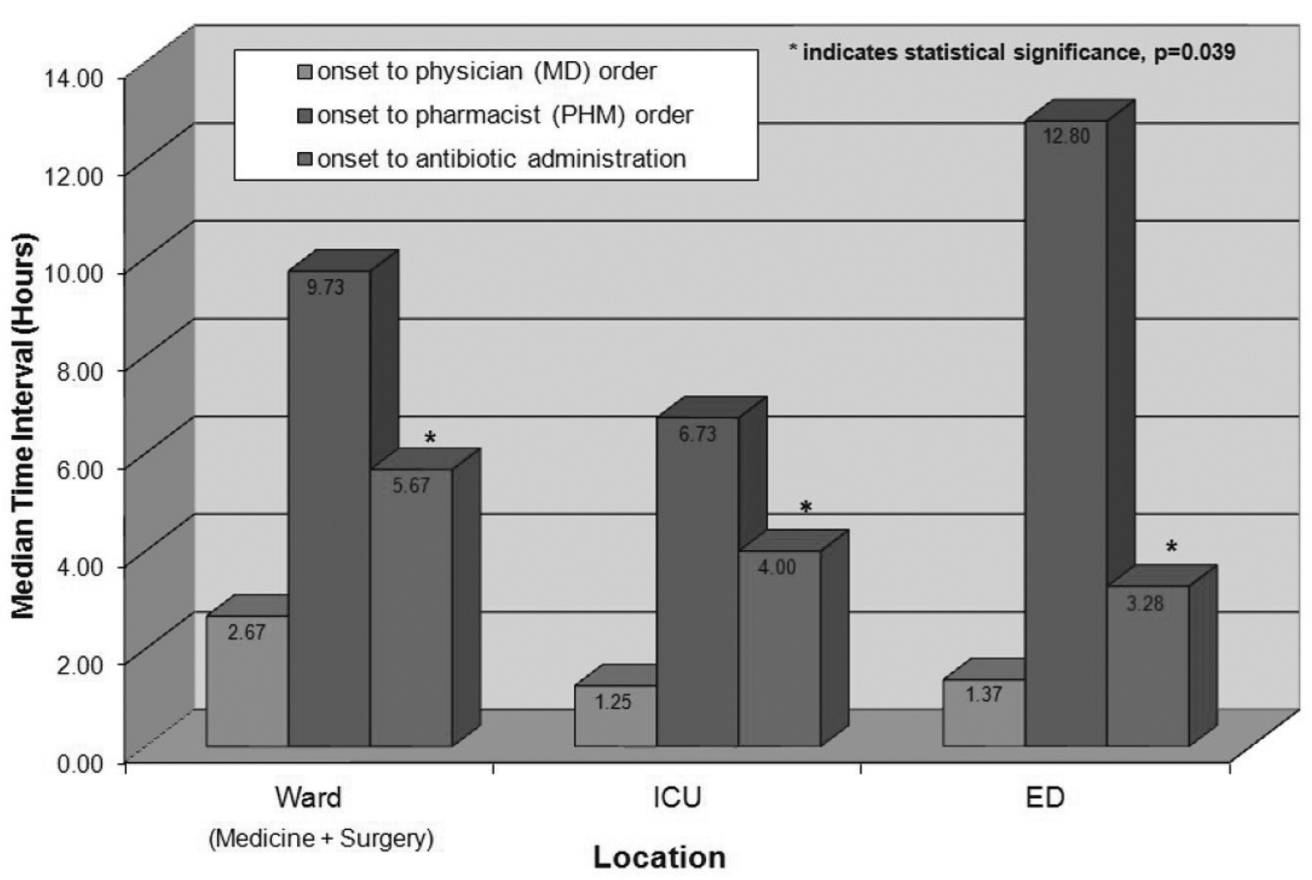

Figure 1. Intervals for stages in the process of antibiotic administration, by location of onset of severe sepsis or septic shock. ED = emergency department, ICU = intensive care unit. 
received appropriate antibiotic therapy within $1 \mathrm{~h}$. Francis and others $^{10}$ found that the time to antibiotic administration among patients with severe sepsis decreased significantly after implementation of a standardized sepsis protocol in the emergency department.

The overall survival rate of $56 \%$ in the current cohort corresponds with rates reported in the available literature. ${ }^{1,2,8} \mathrm{In}$ a previous study of patients with septic shock, Kumar and others $^{8}$ found that administration of effective antimicrobials within the first hour of documented hypotension was associated with a survival rate of $79.9 \%$. Extrapolating from a $7.6 \%$ increase in survival per hour reduction in delay to antibiotic administration (based on results reported by Kumar and others ${ }^{8}$ ) and a 3-h reduction in median interval to effective antibiotics to meet the 1-h recommendation of the Surviving Sepsis Campaign, the potential survival rate for the current cohort was calculated as $78.8 \%$. This theoretical survival rate is notably similar to the survival rate for patients in the study by Kumar and others ${ }^{8}$ who received therapy within $1 \mathrm{~h}$.

The current study expands on previous investigations by examining the delay to antibiotic administration within specific inpatient locations, including general surgery and general medicine wards. Published data have shown a reduction in survival among patients who experienced sepsis in hospital relative to those who presented with sepsis that developed before admission. ${ }^{2}$ This increased mortality rate among patients with nosocomial sepsis has prompted examination of contributing factors, with timeframe to antibiotic administration being the focus of the current study. There was a significant difference in the interval to initiation of antibiotic therapy among patients with onset of severe sepsis or septic shock on the wards, in the ICU, and in the emergency department, with the interval being longest for patients in the wards and shortest for those in the emergency department. Although not unexpected, this result supports the high mortality found among inpatients with sepsis. Probable explanations include delayed recognition of severe sepsis or septic shock because of lower nurse-to-patient ratios in the wards, longer timeframes for drug acquisition from pharmacy, and clinicians' lack of awareness of the impact of early antibiotic administration. However, this difference did not carry over to the interval from recognition of onset of severe sepsis or septic shock to physician order or pharmacist order entry. The lack of a significant difference for these intervals may indicate that staffing and drug supply are not the main barriers to prompt antibiotic administration.

The interval to antibiotic administration in the ICU was greater than the 1 -h recommended timeframe set forth by the Society of Critical Care Medicine, despite familiarity of staff members with these recommendations. In this study, patients' severity of illness was not determined because of a lack of complete information for each patient. As such, it is possible that patients with greater severity of illness, such as those in the
ICU, had greater delays to antibiotic therapy to facilitate initial resuscitative measures. In the study by Kumar and others, ${ }^{8}$ the time from septic shock-related hypotension to effective antibiotic therapy was the variable most strongly associated with mortality, even when fluid resuscitation and APACHE II scores were factored into the multivariate analysis. This finding further emphasizes the importance of early antibiotic administration for patients with severe sepsis or septic shock, regardless of the severity of illness, and stresses identification of strategies to minimize this timeframe.

In the current cohort, the main sources of infection were comparable to those reported in other studies. The high percentage of patients who received appropriate empiric therapy may be attributable to guidelines recommending broadspectrum coverage until treatments can be tailored according to culture results. ${ }^{4}$ At the time of this study, the institution did not have specific inpatient sepsis protocols in place. However, the emergency department had protocols for patients with febrile neutropenia and pneumonia. At this institution, the high proportion of patients with cancer who were receiving broadcoverage antibiotics for febrile neutropenia may have also contributed to high rates of appropriate empiric therapy. When survival rates were compared for subgroups of patients who received appropriate antibiotics and those who did not receive appropriate empiric therapy, there was a clinically relevant trend toward higher survival in the group that received correct empiric antibiotics. Although these results were not statistically significant (because of the small number of patients in the study), the impact of effective antimicrobial therapy on mortality has been substantiated by Gaieski and others, ${ }^{9}$ who observed a lower mortality rate among patients who received appropriate antibiotics in less than $1 \mathrm{~h}$ versus more than $1 \mathrm{~h}$. Appropriate choice of initial antimicrobials, based on patient risk factors, presentation, and regional resistance patterns, remains key to reducing mortality among patients with severe sepsis or septic shock.

This study had several limitations. It was performed at a single centre as a retrospective chart review, a study design with inherent potential for bias and inability to establish direct cause and effect. The results may not be generalizable to other centres where patient population, staffing, and drug distribution may differ. Patients were identified through an initial screening process based on receipt of antibiotics, and there is a possibility that some patients with severe sepsis or septic shock were missed. However, we believe that this screening method captured a broad population of patients with potential sepsis, and allowed identification of all patients with severe sepsis or septic shock during the study period. The calculated time interval depended on accuracy of documentation of the time of the order and the time of administration, and patient charts without documented times were excluded, which led to potential bias. The definition of onset of severe sepsis and 
septic shock represented a rough estimate of initial findings that typically prompt recognition of sepsis, but these findings may not represent the true onset of severe sepsis or septic shock. We were unable to determine patients' severity of illness because of a lack of documented factors in the charts for calculating sequential organ failure assessment (SOFA) scores. This may have had a confounding effect on the interval to antibiotic administration, as patients who are more ill may have undergone other interventions before receiving antibiotic therapy. Finally, the small sample size for patients who experienced severe sepsis or septic shock on the wards and for those who had administration times of less than $1 \mathrm{~h}$ may have contributed to lack of significance in the survival analysis.

\section{CONCLUSION}

For this sample of inpatients, the time from recognition of onset of severe sepsis or septic shock to antibiotic administration exceeded the 1-h recommendation set forth by the Surviving Sepsis Campaign. This finding, coupled with the knowledge that timely administration of appropriate antibiotics affects survival rates, has prompted changes to current management strategies at the study hospital to expedite antibiotic therapy. Since the study was performed, strategies such as identifying antibiotics that can be administered via IV push or bolus have been employed in an effort to minimize this interval at the study institution. Examination of individual components of the process of antibiotic administration, such as a time-and-motion study, may be beneficial to determine future quality improvement initiatives from a system viewpoint.

\section{References}

1. Martin C, Priestap F, Fisher H, Fowler RA, Heyland DK, Keenan SP, et al.; STAR Registry Investigators. A prospective, observational registry of patients with severe sepsis: the Canadian Sepsis Treatment and Response Registry. Crit Care Med. 2009;37(1):81-8.

2. In focus: a national look at sepsis. Ottawa (ON): Canadian Institute for Health Information; 2009. 14 p.

3. Rivers E, Nguyen B, Havstad S, Ressler J, Muzzin A, Knoblich B, et al.; Early Goal-Directed Therapy Collaborative Group. Early goal-directed therapy in the treatment of severe sepsis and septic shock. N Engl J Med. 2001;345(19):1368-77.

4. Dellinger R, Levy M, Carlet JM, Bion J, Parker MM, Jaeschke R, et al. Surviving Sepsis Campaign: international guidelines for management of severe sepsis and septic shock: 2008. Crit Care Med. 2008;36(1):296-327.

5. Nguyen H, Smith D. Sepsis in the 21st century: recent definitions and therapeutic advances. Am J Emerg Med. 2007;25(5):564-71.

6. Nguyen HB, Corbett SW, Menes K, Cho T, Daugharthy J, Klein W, et al. Early goal-directed therapy, corticosteroid, and recombinant human activated protein $\mathrm{C}$ for the treatment of severe sepsis and septic shock in the emergency department. Acad Emerg Med. 2006;13(1):109-13.

7. Green R, Djogovic D, Gray S, Howes D, Brindley PG, Stenstrom R, et al; CAEP Critical Care Interest Group. Canadian Association of Emergency Physicians sepsis guidelines: the optimal management of severe sepsis in Canadian emergency departments. CJEM. 2008;10(5):443-59.

8. Kumar A, Roberts D, Wood KE, Light B, Parrillo JE, Sharma S, et al. Duration of hypotension before initiation of effective antimicrobial therapy is the critical determinant of survival in human septic shock. Crit Care Med. 2006;34(6):1589-96.
9. Gaieski D, Mikkelsen M, Band RA, Pines JM, Massone R, Furia FF, et al. Impact of time to antibiotics on survival in patients with severe sepsis or septic shock in whom early goal-directed therapy was initiated in the emergency department. Crit Care Med. 2010;38(4):1045-53.

10. Francis M, Rich T, Williamson T, Peterson D. Effect of an emergency department sepsis protocol on time to antibiotics in severe sepsis. CJEM. 2010;12(4):303-10.

11. Mathevon T, Souweine B, Traoré O, Aublet B, Caillaud D. ICU-acquired nosocomial infection: impact of delay of adequate antibiotic treatment. Scand J Infect Dis. 2002;34(11):831-5.

12. Natsch S, Kullberg B, van der Meer JW, Meis JF. Delay in administering the first dose of antibiotics in patients admitted to hospital with serious infections. Eur J Clin Microbiol Infect Dis. 1998;17(10):681-4.

13. American College of Chest Physicians/Society of Criticial Care Medicine Consensus Conference: definitions for sepsis and organ failure and guidelines for the use of innovative therapies in sepsis. Crit Care Med. 1992;20(6):864-74.

14. Levy MM, Fink MP, Marshall JC, Abraham E, Angus D, Cook D, et al. 2001 SCCM/ESICM/ACCP/ATS/SIS International Sepsis Definitions Conference. Crit Care Med. 2003;31(4):1250-6.

15. Gacouin A, Le Tulzo Y, Lavoue S, Camus C, Hoff J, Bassen R, et al. Severe pneumonia due to Legionella pneumophilia: prognostic factors, impact of delayed appropriate antimicrobial therapy. Intensive Care Med. 2002;28(6):686-91.

16. Iregui M, Ward S, Sherman G, Fraser VJ, Kollef MH. Clinical importance of delays in the initiation of appropriate antibiotic treatment for ventilator-associated pneumonia. Chest. 2002;122(1):262-8.

17. Proulx N, Fréchette D, Toye B, Chan J, Kravcik S. Delays in the administration of antibiotics are associated with mortality from adult acute bacterial meningitis. QJ Med. 2005;98(4):291-8.

18. Houck PM, Bratzler DW, Nsa W, Ma A, Bartlett JG. Timing of antibiotic administration and outcomes for Medicare patients hospitalized with community-acquired pneumonia. Arch Intern Med. 2004;164(6):637-44.

19. Miner JR, Heegaard W, Mapes A, Biros M. Presentation, time to antibiotics, and mortality of patients with bacterial meningitis at an urban county medical center. J Emerg Med. 2001;21(4):387-92.

20. Lodise TP, McKinnon PS, Swiderski L, Rybak MJ. Outcomes analysis of delayed antibiotic treatment for hospital acquired Staphylococcus aureus bacteremia. Clin Infect Dis. 2003;36(11):1418-23.

Katie Mok, BScPhm, ACPR, RPh, is with Mount Sinai Hospital, Toronto, Ontario.

Michael D Christian, MD, MSC, FRCP, is with Mount Sinai Hospital, Toronto, Ontario.

Sandra Nelson, PharmD, RPh, is with Mount Sinai Hospital, Toronto, Ontario.

Lisa Burry, BScPharm, PharmD, RPh, is with Mount Sinai Hospital, Toronto, Ontario.

Competing interests: None declared.

Address correspondence to:

Katie Mok

Department of Pharmacy

Mount Sinai Hospital

600 University Avenue

Toronto ON M5G 1X5

\section{e-mail: kmok@mtsinai.on.ca}

Acknowledgements: We express our appreciation to Maedean Brown, Department of Critical Care Medicine, Mount Sinai Hospital, Toronto, Ontario, for her assistance with data management and analysis and to Dr. Sangeeta Mehta, MD, ICU Research Director, Mount Sinai Hospital and University of Toronto, Toronto, Ontario, for her support and advice. 